\title{
The benefit of second eye cataract surgery
}

\begin{abstract}
Purpose/Method We prospectively assessed the binocular functions of $\mathbf{5 0}$ patients before and after second eye cataract surgery to determine whether limiting cataract surgery to the first eye was justified or not.

Results After the first cataract operation $88 \%$ of operated eyes had a visual acuity of $6 / 12$ or better but only $52 \%$ met the UK Driver and Vehicle Licensing Agency (DVLA) driving standard for visual acuity and field. Following second eye cataract surgery, visual acuity of the second eye was better than the first in $42 \%$ of patients. Moreover, $60 \%$ of patients had an improved binocular visual acuity after their second eye operation. Ocular dominance changed in $44 \%$ of cases. Stereo acuity improved from $32 \%$ after first eye surgery to $\mathbf{9 0 \%}$ after second eye surgery. Binocular horizontal field of vision improved by $20^{\circ}$ or more in $54 \%$ of patients and binocular vertical field of vision improved in $36 \%$ after second eye surgery. The proportion of patients meeting the DVLA driving standard improved from $52 \%$ after first eye surgery to $86 \%$ after second eye surgery.

Conclusion Surgery on the second eye for cataract improves binocular function and enables a greater proportion of patients to meet the DVLA driving standard by expanding their horizontal field.
\end{abstract}

Key words Automobile driver examination, Cataract extraction, Contrast sensitivity, Depth perception, Vision, binocular, Visual acuity, Visual field

Cataract is an important cause for morbidity in later life. Surgery for cataract in the UK is performed in $1.4 \%$ of the population over 65 years. ${ }^{1}$ Cataract surgery is successful: $80 \%$ of patients achieve a visual acuity of $6 / 12 .^{2}$

However, cataracts are predominantly bilateral ${ }^{3}$ and if surgery is not performed for the second cataract, significant functional problems persist. ${ }^{4-6}$ Patients who have surgery for both cataracts function better and have less decline in vision subsequently. ${ }^{1}$ Binocular contrast sensitivity ${ }^{5,7}$ and stereo acuity ${ }^{8}$ are improved by surgery to both cataracts. Cataracts are known to depress visual field fairly uniformly. Though clinical grading of cataract is a poor predictor of
Table 1. Visual assessment performed on both eyes, before and after cataract surgery

Monocular and binocular Snellen acuity

With and without spectacles

Monocular and binocular Pelli-Robson contrast sensitivity

Ocular dominance

Stereo vision

Fusion

Simultaneous perception

Suppression

Binocular Lister perimetry fields of vision

visual field loss, posterior subcapsular opacity and pre-operative visual acuity correlate significantly with post-operative central field recovery. ${ }^{9}$ The central region of the visual field has the greatest threshold recovery after cataract surgery. ${ }^{10}$ Yao and Flammer ${ }^{11}$ reported a correlation of visual field with cataract density, though this is not uniformly accepted. ${ }^{12}$ Our medical care for cataract patients is comparable to the UK NHS Survey. ${ }^{13}$ For borderline cases functional impairment is subjectively assessed using the VF.14 questionnaire. ${ }^{14}$

\section{Materials and methods}

Patients attending the eye clinic in a general hospital who had been listed for second eye cataract surgery but had no other eye complaints were considered for the study. Patients who consented to undertake pre- and post-operative visual assessments were referred to the orthoptic department. The tests performed (Table 1) were repeated by the same orthoptist after second eye cataract surgery.

\section{Results}

The principal results are summarised in Table 2. Fifty patients were recruited (age 47-90 years, mean 73 years; $64 \%$ female). The time interval

Table 2. Binocular visual functions after cataract surgery

\begin{tabular}{lcc}
\hline Visual function & $\begin{array}{c}\text { After first } \\
\text { eye surgery } \\
(\%)\end{array}$ & $\begin{array}{c}\text { After second } \\
\text { eye surgery } \\
(\%)\end{array}$ \\
\hline Simultaneous perception & 62 & 100 \\
Fusion & 50 & 100 \\
Stereopsis & 32 & 90 \\
Binocular driving acuity & 82 & 100 \\
Binocular driving field & 70 & 86 \\
DVLA driving standard & 52 & 86 \\
\hline
\end{tabular}

All binocular visual functions improved following second eye cataract surgery.

\author{
E.M. Talbot \\ A. Perkins \\ Royal Preston Hospital \\ Preston, UK \\ E.M. Talbot \\ Department of \\ Ophthalmology \\ Royal Preston Hospital \\ Sharoe Green Lane \\ Preston PR2 9HT, UK \\ Tel: $+44(0) 1772710397$ \\ Fax: +44(0)1772 710957
}




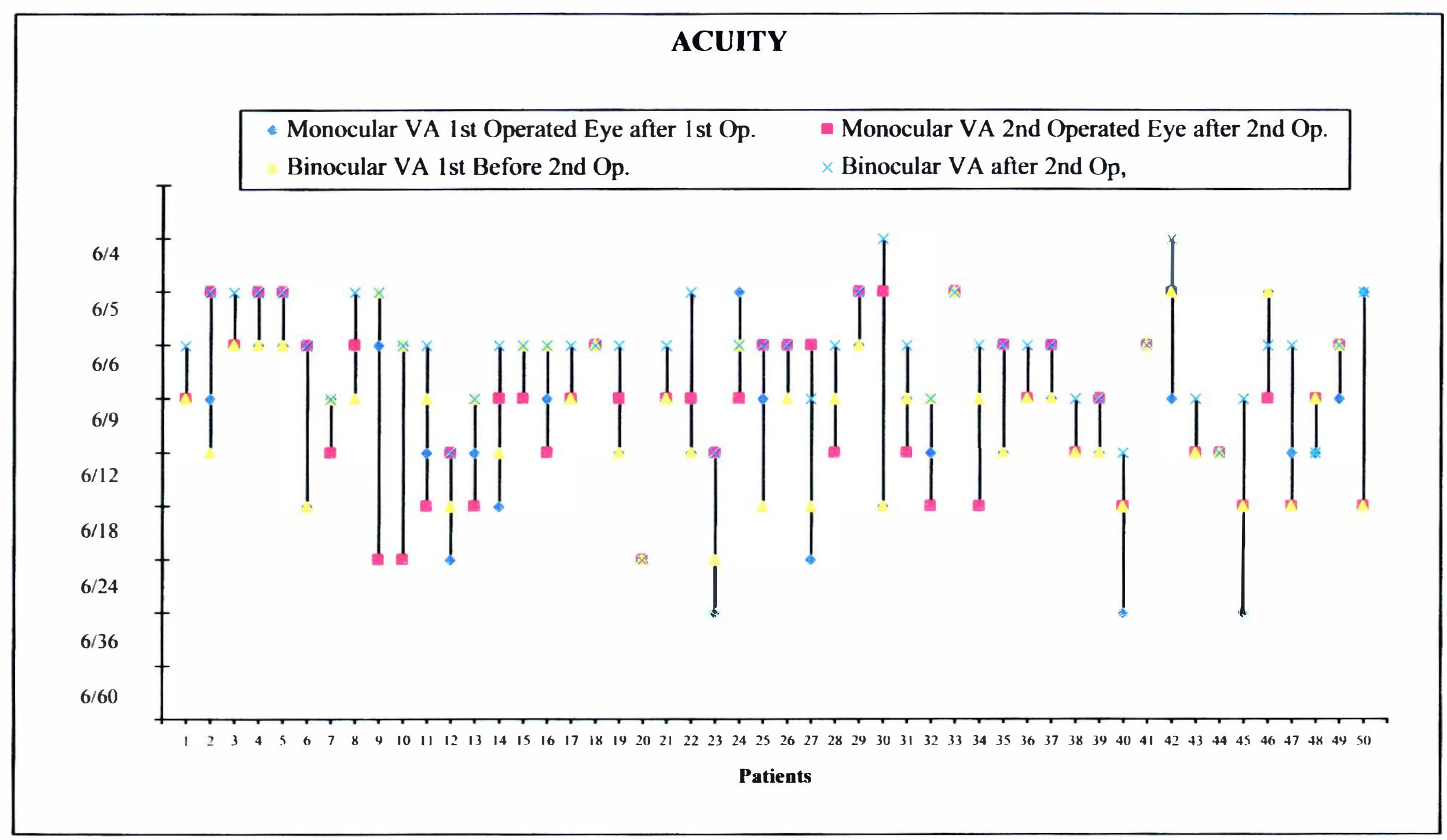




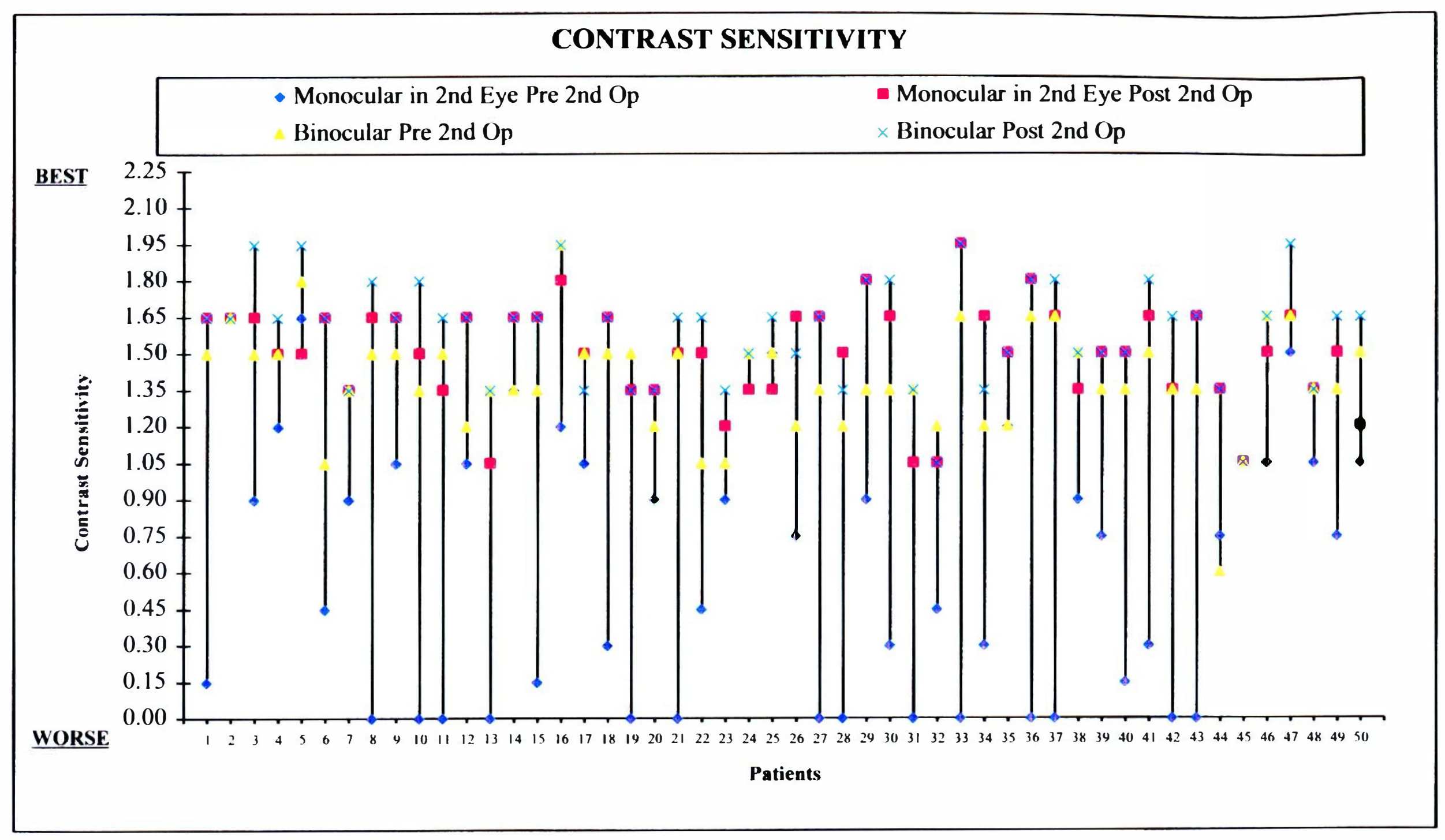

Fig. 2. Contrast sensitivity changes after second eye cataract surgery. 


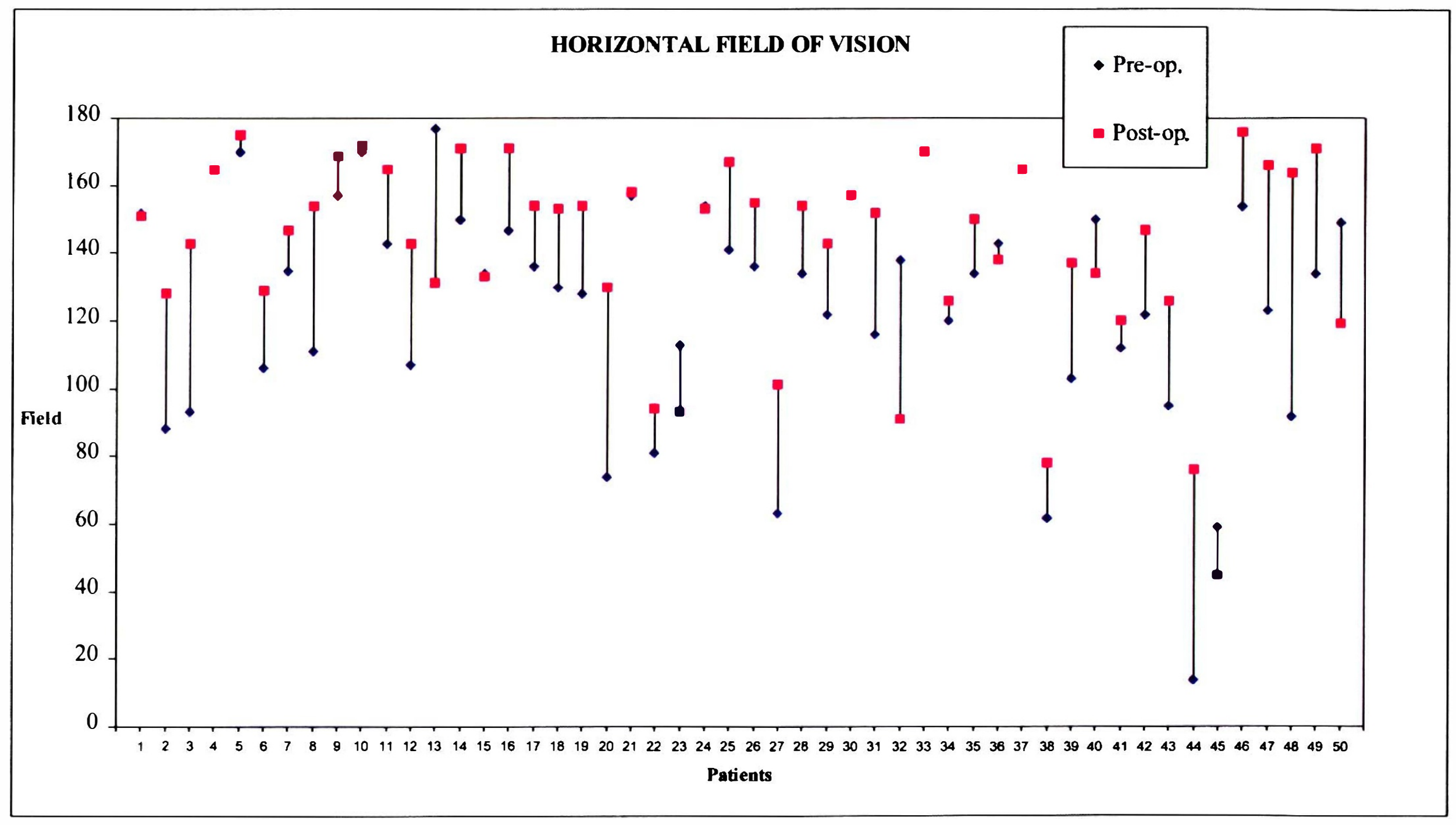




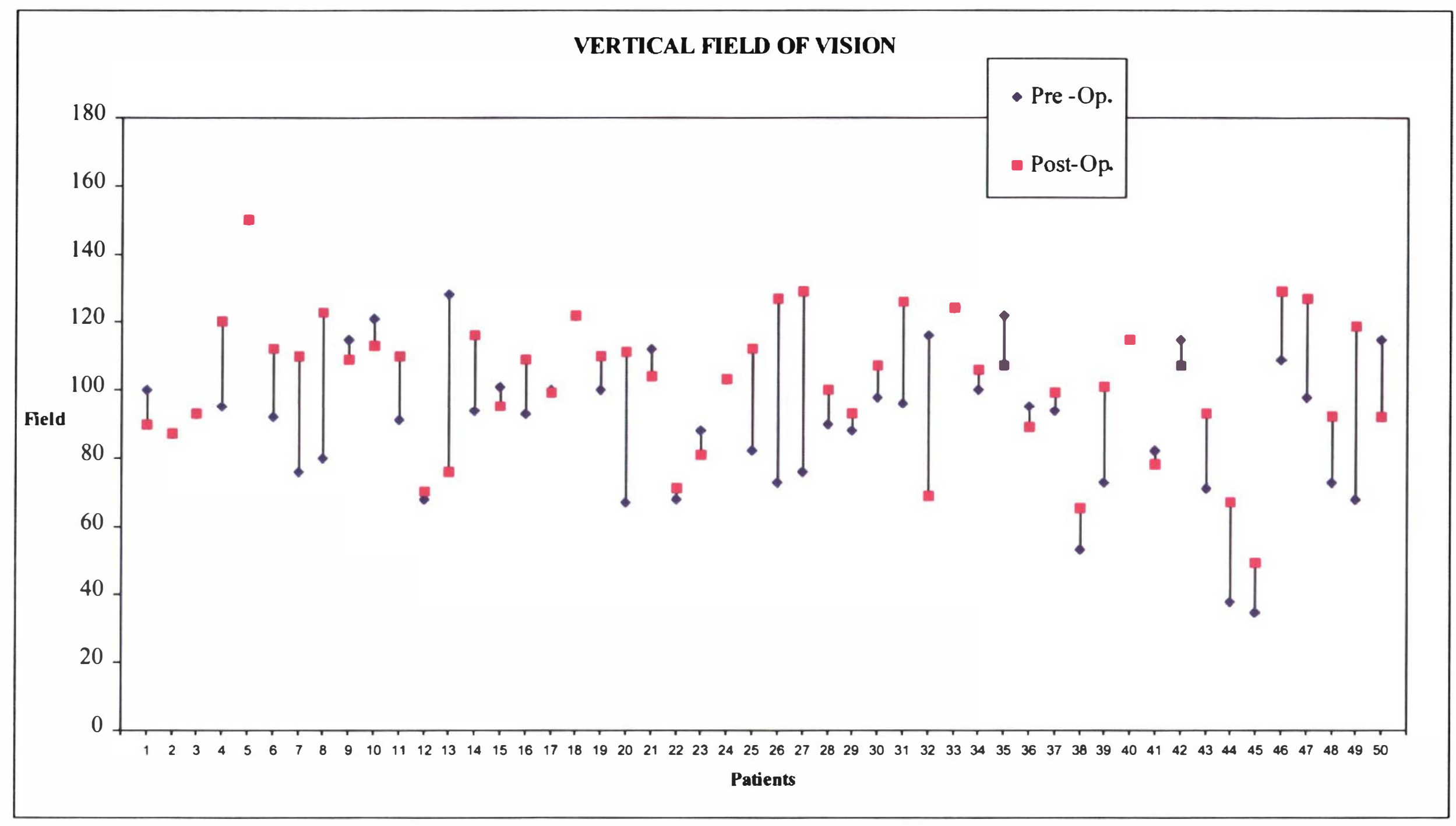

Fig. 4. Vertical binocular visual field changes after second eye cataract surgery. 
between first and second assessment was 3-16 months (mean 7.5 months, mode 4 months). A total of 83 patients were initially referred for study, 50 of whom completed the assessments. (Thirteen patients did not attend for post-operative assessment, 10 patients had surgery prior to pre-operative assessment, 6 patients had the operation cancelled, 3 patients died before completion of study and 1 patient had poor comprehension of the tests.)

At the first binocular function assessment, $82 \%$ of first operated eyes had a visual acuity of $6 / 12$ or better aided. At the second assessment after second eye surgery, the first eye results had improved to $88 \%$. However, only $52 \%$ of second eyes had a visual acuity of $6 / 12$ or better a few months after surgery. Of those with an acuity less than $6 / 12$ with both eyes open prior to second eye cataract surgery, all achieved $6 / 12$ post-operatively. Forty-two per cent of second operated eyes achieved better visual acuity than first operated eyes. (Ocular dominance changed in $44 \%$.) Moreover, $66 \%$ of patients had an improved binocular visual acuity after their second eye operation. Details of acuity changes are shown in Fig. 1.

The contrast sensitivity of the second eye after surgery showed a mean change of $0.85 \mathrm{log}$ units (range -0.15 to 1.95 (2.1)). The binocular improvement of contrast sensitivity was less marked, at $0.21 \log$ units $(-0.15$ to $0.75(0.9)$ ) (Fig. 2). Stereo acuity was observed in $32 \%$ following first eye surgery and $90 \%$ after second eye surgery (36\% had 240 seconds of arc or better). Binocular field of vision improved by $20^{\circ}$ or more horizontally in $54 \%$ of patients ( $8 \%$ were worse) (Fig. 3 ) and vertically in $36 \%$ (6\% were worse) (Fig. 4$)$.

Visual functions for driving changed after second eye surgery. There were $48 \%$ of patients who initially failed the UK Driver and Vehicle Licensing Agency (DVLA) group I requirements: $18 \%$ for acuity and $30 \%$ for visual field. However, following second eye surgery no patient had a binocular acuity worse than $6 / 12$ and only $14 \%$ failed the visual field assessment. Second eye cataract surgery improved the percentage fit to drive from $52 \%$ to $86 \%$.

\section{Discussion}

Laidlaw and Harrad ${ }^{5}$ have demonstrated an improvement in binocular visual acuity, contrast sensitivity and stereopsis after second eye cataract surgery. Yao and Flammer ${ }^{11}$ quantified cataract density using an opacity lens metre and showed a linear relationship with recovery of depth of field following cataract surgery. Our study quantifies width and height of field improvement following second eye surgery, and confirms previous findings of improved binocular function.

Eighty-two per cent of first eyes achieved a Snellen acuity of $6 / 12$ or better, as expected. ${ }^{2}$ At the second assessment a further improvement was seen, $88 \%$ having a visual acuity of $6 / 12$ or better after first eye surgery. These good results contrast with only $52 \%$ of second eyes having an acuity of $6 / 12$ or better soon after surgery. We would expect these results to improve with time, as demonstrated by the first eye. Thus the improvements in binocular functions, acuity, contrast sensitivity and field were even more impressive given that they are achievable at an early (suboptimal) stage.

The monocular contrast sensitivity of every second eye improved dramatically after surgery. The binocular contrast sensitivity improved in $74 \%$ of patients. However, the binocular improvement of contrast sensitivity was generally small in comparison with the monocular contrast sensitivity. That is, the second cataract did not dramatically reduce binocular contrast sensitivity so there was only a small gain in binocular contrast sensitivity after second eye surgery.

\section{Conclusions}

After second eye cataract surgery binocular visual fields are improved horizontally and vertically and binocular acuity is improved, enabling a greater proportion of patients to meet the UK DVLA driving standard. Horizontal visual field impairment, rather than inadequate acuity, is the limiting factor for meeting the driving standard in this group of patients.

All the parameters examined improved significantly after second eye cataract surgery. This study supports the conclusion by Claridge et al. ${ }^{15}$ that second eye cataract surgery should not be rationed.

We thank Judith Burn, Janice Kerr, Gill Kerry, Jane Robertson, Carol Buckley, Christine Banik, Rebecca Gilmour, John Bennett, Paul Walsh and Deb Jacobs for their help.

\section{References}

1. Department of Health. Hospital episode statistics date 1993-94. Unpublished data provided by the Department of Health, London.

2. Desai P. The National Cataract Surgery Survey. II. Clinical outcomes. Eye 1993;7:489-94.

3 Leibowitz HM, Krueger D, Maunder L, et al. The Framingham eye study monograph. Surv Ophthalmol 1980;Suppl:333-63.

4. Hillbourne JFH. Social and other aspects of adjustment to single eye cataract extraction in elderly patients. Trans Ophthalmol Soc UK 1975;95:254-9.

5. Laidlaw A, Harrad R. Can second eye cataract extraction be justified? Eye 1993;7:680-6.

6. Javitt J, Brenner M, Curbow B, et al. Outcomes of cataract surgery. Improvement in visual acuity and subjective visual function after surgery in the first, second and both eyes. Arch Ophthalmol 1993;111:686-91.

7. Bissen-Miyajima H, Katsumi O, Shimbo R, Guang JW, Hara E. Contrast visual acuities in cataract patients. III. Changes of contrast acuity profiles in normal and pathological eyes. Acta Ophthalmol Scand 1995;73:50-5.

8. Sawusch MR, Guyton DL. Optimal astigmatism to enhance depth of focus after cataract surgery. Ophthalmology 1991;98:1025-9.

9. Lam BL, Alward WLM, Kolder HE. Effect of cataract on automated perimetry. Ophthalmology 1991;98:1066-70.

10. Guthauser U, Flammer J. Quantifying visual field damage in cataract. Am J Ophthalmol 1988;106:480-4.

11. Yao K, Flammer J. Relationship between cataract density and visual field damage. Eur J Ophthalmol 1993;3:1-5. 
12. Stewart WC, Rogers GM, Crinkley CM, Carlson AN. Effect of cataract extraction on automated fields in chronic open-angle glaucoma. Arch Ophthalmol 1995;113:875-9.

13. Desai P. The National Cataract Surgery Survey: III. Process features. Eye 1993;7:667-71.
14. Steinberg E, Tielsch J, Schein O, et al. The VF-14: an index of functional impairment in patients with cataract. Arch Ophthalmol 1994;112:630-8.

15. Claridge KG, Francis PJ, Bates AK. Should second eye surgery be rationed? Eye 1995;9:47-9. 